Yaratıc Drama Dergisi

2007, Cilt 1, say1 3-4

\title{
Yaratıcı Drama ile Örtüşen Çağdaş Sanat Akımları
}

\author{
Ayşe ÇAKIR ÍLHAN.
}

Ankara Üniversitesi

\begin{abstract}
Özet
Bu makalede yaratıcı dramanın eğitim yaklaşımı ile günümüz sanat anlayışlarındaki benzerlikler tartışılmış; Avant-garde Sanat, post-modernizmin, dada, kavramsal sanat, fluxus, çevresel sanat, oluşumlar gibi kavramlar ve sanat akımları tanımlanarak yaratıcı drama alanı ile örtüşen yönleri vurgulanmaya çalışılmıştır. Son olarak iki bienal (İstanbul ve Venedik 2007) örnek olarak verilmiştir.
\end{abstract}

Anahtar sözcükler: Yaratıcı drama, çağdaş sanat akımları

\begin{abstract}
This article discusses the similarities between the educational approach of creative drama and modern trends of art; defines concepts and trends such as Avant-garde art, post-modernism, dadaism, conceptual art, fluxus, land art, happenings; and emphasizes their similarities with creative drama. Finally two biennials (Istanbul and Venice 2007) were mentioned as examples.
\end{abstract}

Keywords: Creative drama, modern trends of art

Prof. Dr., Ankara Üniversitesi, Eğitim Bilimleri Fakültesi, E-posta: ilhan@education.ankara.edu.tr 


\section{Giriş}

Yaratıcıllğı, bilinen şeylerden yararlanarak yepyeni bir şey ortaya koymak olarak tanımlarsak, yaratıcılık eğitiminin yalnızca okuldaki etkinliklerle sınırlı olmadığını anlarız. Yaratıcılık kişinin çevresini yorumlayabildiği her yerde ortaya çıkabilir. Ancak yaratıcılığın yorucu, bir o kadar da eğlenceli olduğu da bilinen bir gerçektir. Çünkü yaratıcılık yeni fikirleri, eğlenceleri, sürprizleri içerisinde barındırır. Yaratıcılık aynı zamanda içerisinde çatışmayı da barındırır. Yaratıcı düşüncenin diğer var olan düşüncelerden farkı, değişik olmasıdır.

Yaratıcılığın gelişmesinde bilindiği gibi sanat eğitiminin önemli bir yeri vardır. Yaratıcı drama eğitimi de aynı zamanda bir sanat eğitimidir. Drama, tüm sanat alanları ile iç içedir. Drama ile ilgilenen biri sanat olaylarını, sanat kuramlarını, sanat akımlarını, sanat eleştirilerini takip etmeli; tiyatro, bale, konser, sergi vb. etkinliklere katılmalı, bunları izlemeli, en azından bunlardan haberdar olmalıdır. Yaratıcılık ve sanat eğitimi ile ilgilenen herkes aşağıda açıklanacağı gibi sanatın tarih boyunca geçirdiği değişimleri, özellikle de günümüz sanatını bilmek ve yapacağı sanatsal çalışmalarda bu değişimlerden yararlanmak durumundadır.

İnsanlık kadar yaşa sahip olan sanat, tarih boyunca bazen dış çevreye, bazen sanatçının iç dünyasına, bazen sadece sanat yapıtınına, bazen de onu alımlayana yönünü çevirmiştir. Sanatçı, sanat yapıtı, alımlayıcı ve dış çevre, sanatın olmazsa olmaz parçalarını oluşturur. Sanatın olmazsa olmaz bu parçalarından biri zaman zaman ön plana çıkmış ve değişik sanat kuramlarını ve akımlarını oluşturmuştur. Örneğin Milattan Önceki dönemlerden 19.yüzyıla kadar sanatçı dış dünyada olup bitenleri yansıtmaya çalışmıştır. "Yansıtmacı Sanat Kuramı" olarak adlandırılan bu anlayıştaki sanatçılar bazen dış dünyayı olduğu gibi, bazen kendine göre düzelterek ve düzenleyerek, bazen de genelleyerek yansıtmıştır. Platon'nun ve Aristo'nun görüşleri bu dönemlerde etkili olmuştur. Rönesans'ta Aristo'nun görüşleri yeniden yorumlanmış, ideal güzellik ve genel olan yansıtılmaya çalışılmıştır. Rönesanstan sonra sanat, yönünü toplumsal yaşama da çevirmiş gündelik yaşam, hatta emekçiler sanatta yansıtılmaya çalışılmıştır. 19.yüzyıla kadar sanat "Yol boyunca gezdirilen bir ayna" olarak tanımlanmış ve sanatın işlevi dış dünyada olup bitenlerin yansıtılması olarak yorumlanmıştır.

Sanat 19. yüzyılın ikinci yarısında yönünü sanatçıya çevirmiş ve sanat; sanatçının iç dünyasına açılan bir pencere olarak nitelendirilmiştir. İzlenimcilik (empresyonizm), dişavurumculuk (ekspresyonizm) ve bu akımlara bağlı Köprü Grubu (Die Brücke), Vahşiler Grubu (Fovizm), Mavi Atlı Grubu (Der Blau Reiter) gibi sanat yaklaşımlarında sanatçı dış dünyada olup bitenlerden çok, kendi duygu ve düşüncelerini anlatmaya ve aktarmaya çalışmıştır. 
19.yüzyıldan sonra sanatta yeni bir bakış açısı ortaya çıkmış ve sanat yapıtı ön plana çıkmıştır. Bu dönemde sanatçı yeni bir sanat dili oluşturmaya çalışmış, soyuta doğru bir eğilim göstermiştir. Sanatçı artık gördüğünden değil bildiğinden yola çıkmıştır. Sanat için bir dönüm noktası oluşturan bu yaklaşım kübizm sanat akımı ile yeni bir ivme kazanmıştır. Kübizm akımı dış dünyadaki nesneleri geometrik biçimler "üçgen, koni, kare, silindir v.b." şeklinde göstermeye çalışmıştır. Çocukların ve ilkellerin düşünme biçimleri bu yaklaşımda etkili olmuştur. Karmaşık bir yapının hakim olduğu kübizm akımının en önemli temsilcileri Picasso ve Braque'dir. Biçimsel çözümlemeler, anlamsızlığa yönelme, doğayı yeniden yorumlama eğilimleri sanatçıları bu dönemde yeni teknik ve yöntem arayışlarına itmiştir. Sanatçılar biçim bozmaları ve mecazlarla (eğretileme) düşüncelerini anlatmaya çalışmışlardır.

I. Dünya Savaşı (1914) sırasında İngiltere, Fransa ve Almanya'daki pek çok savaş karşıtı sanatçı İsviçre'ye kaçarlar. İsviçre savaşa katılmaz. Orada tiyatrocular, ressamlar, balerinler ve pek çok sanat alanından sanatçılar bir araya gelerek Dadaizm hareketini başlatırlar. Savaşa karşı olan bu akım diğer çağdaş akımlara öncü olmuştur denilebilir. Dadaistler sanat alanları arasındaki sınırları ortadan kaldırıp disiplinler arası çalışmalar, gösteriler yapmışlardır. Amaçları farklı olsa da yaratıcı dramadaki gibi doğaçlamalar ve oluşumlar yolu ile düşüncelerini gerçekleştirmişlerdir.

Bir dada sanatçısı olan Marcel Duchamp; sanatta çağdaş akımların gerçek öncüsüdür. Ressam ve felsefecidir. Sanatın ne olduğunu sorgulamaya çalışan Duchamp'a göre sanat insanların acı çekmesine engel olmamış Dünya savaşının çıkmasını engelleyememiştir. Avrupa'daki Milliyetçi yaklaşımlar pek çok insanın (sanatçıların da) acı çekmesine neden olmuştur.

I. Dünya savaşı sonrasında Paris’te "Yeni Eğilimler Sergisi” adı ile bir sergi açılır. Bu sergiye kübist, dadaist ve kavramsal sanat akımlarının sanatçıları çağrılmıştır: Duchamp bu sergiye bir "pisuar" gönderir (Resim 1). Sanayi nesnesi olan pisuar, sergi komitesini çok şaşırtmıştır. Çünkü sergiye bu pisuar bir sanat nesnesi olarak gönderilmiştir. Bir sanat nesnesi ya da hazır nesne olarak pisuar, o dönemde büyük tartışmalara yol açmıştır. Bir pisuar, sanat nesnesi (yapıtı) olabilir mi? Sanat yapıtı neye denir? Bu ve benzeri sorular o dönemde sorgulanır. Artık resim; tuval ve yağlıboya ile sınırlı değildir. Heykel; mermer ve tahtadan ibaret değildir. Sanat insanın yaratıcılığına bağlıdır. Her şey sanata malzeme olabilir. Sanat parayla alınıp satılamaz. 


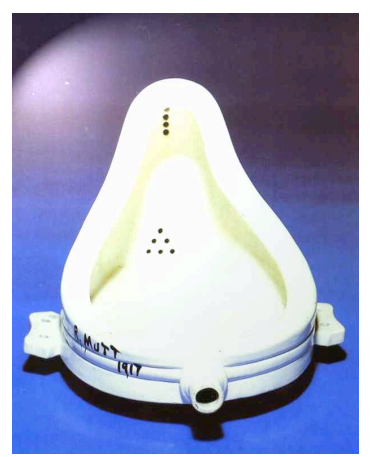

Resim 1: Marcel Duchamp (Pisuar)

Sanatın başka bir bakış açısı ile ele alınmasını sağlayan Duchamp ve dada hareketi günümüz sanat anlayışında büyük rol oynamıştır. Aşağıda günümüz sanat anlayışlarına örnek olabilecek ve yaratıcı drama çalışmalarında yararlanılabilecek sanat yaklaşımlarına kısaca yer verilmiştir:

Avant-Garde Sanat: Öncü ya da ilerici sanat anlamına gelen bu terim Fransızca'da "savaşta önde giden asker" sözünden alınmıştır. Avant-Garde, siyasal ve kültürel alanlarda gelenekçi ve yenilikçi tavırların çatışmasıyla bu dönemde belirlenmiş bir sanat ideolojisinin yol açtığı kavram ve uygulamalardır. Avant-Garde temelde, yaşamın her an değişim içinde olduğu inancından yola çıkar. Bu inanç siyasal düzeyde tutucu bir toplum yapısına ve "statüko" değerlerine karşı olmayı getirdiği için, değişken bir toplumsal yapının temelini oluşturan çoğunluğa hizmet etmeyi amaçlar.

Avant-Garde'ın en büyük önemi uyarıcı işlevindedir. Toplum, avant-garde'ın karşısında yadırgamasını giderek ilgisizliğe dönüştürmüştür. 20.yy.'da avant-garde sanatçılar yaşamın ve gerçeğin her an değiştiği ve bilinmeyeni getirdiği, bunu anlatmak içinse sanatçının görsel ve sözel olarak yeni bir dil yaratması gerektiği varsayımından yola çıkmışlardır.

Kapsamcılık avant-garde yaklaşımın önemli bir tavrıdır; estetik ve ahlaki değerlerin belirli kültürel ve kuramsal sınırlar içinde belirlendiği, sınırlar (kapsam) değiştikçe değerlerin de değişebileceği gerçeği, avant-garde sanatın sürekli olarak irdelediği bir kavram ve olgudur.

Sanat alanı sürekli olarak sınırlarını genişletmekte ve sonsuz sayıda şeyi tanımı içine alabilecek bir kapsamlılık kazanmaktadır. 20.yy.'daki birçok sanat akımını avant-garde olarak tanımlayabiliriz.

Dadacılık, Gerçeküstücü Sanat, Serbest Biçimli Sanat, Soyut-Dışavurumculuk, Yoksul Sanat, Hurda Sanatı, Birleştirme'nin Bazı Türleri, Dehşet Sanatı, Oluşumlar, Kavramsal Sanat, Işıı Sanatı, YeniGerçekçilik, Süreç Sanatı, Kendi Kendini Yok Eden Sanat, Çevre Sanatı, Yerleştirme, Yeryüzü Sanatı, Beden Sanat1, vb. olarak sıralanabilir. 
Avant-Garde Sanat Uygulamaları İçin Şu Genellemeler Yapılabilir:

1. Avant-Garde sanat seyredilmeyi değil, izleyicinin katılımını öngörmektedir.

2. Aslolan yaratılan nesne değil bunun oluşturulması ve algılanmasıdır. Dolayısıyla asıl amaç düşünceyi, algıyı, tepkiyi etkilemektir. Yani yaratı (sanat), insan zihninde gerçekleşmektedir.

3. Değerler sorgulandığından genel anlamıyla politiktir.

4. Bir sorgulama yöntemidir; kesin yargılar ve değerler ortaya koymaz.

5. Sanat nesnesi değil, onun yaratılma süreci önceliklidir.

6. Usçu ve kalıpçı düşünceye karşıdır.

7. Özgünlük ve kopya sorunlarını irdeler.

8. Sanatı kapsamcı bir yaklaşımla ele alır.

9. Sanatın sınırlarını içerik, gereç ve tanım açılarından cesaretle yıkar.

10. Biçimciliğe ve estetik amaçlılığa karşıdır.

11. Sanatın meta değerine, alınıp satılabilirliğine karşıdır.

12. Avant-Garde sanatın olduğu toplumda sanatçı bir azınlıktır.

13. Sanal ve olağanın özgünlüğünü vurgular (Erzen, 1997).

Yaratıcı drama çalışmalarına baktığımızda da sonuçtan çok sürecin, seyredilmekten çok katılımın, yaşanan sürecin sorgulanmasının, kesin yargılar ve değerler otaya koymak yerine eleştirinin ve yaratıcı düşüncenin geliştirilmesinin öncelikli olduğu vurgulanır.

Avant- garde sanat anlayışı ile büyük benzerlik gösteren bir başka kavram ise post-modernizm sanat akımıdır. Post-modernizmin özelliklerini ise şöyle sıralayabiliriz:

1. Modernizm içindeki kavramların yeniden sorgulanması, yeniden değerlendirilmesi sürecidir.

2. Post-modernizm; modernizmin yıkıcılığını yapmaz. Modernist akımları ele alır, onları bugünün bakış açısı ile irdeler, yeni bir senteze götürmeye çalışır ve her "post" ekinde olduğu gibi başlangıçtaki ilkelerden sapma, yozlaşma anlamını da içerir.

3. Post-modernizmde geçmiş özgürce kullanılıp, tüketilir.

4. Post-modernizm araştırmaya ve deneye açıktır.

5. Post-modernizmde çok seslilik hakimdir, bütün mevcut seçenekler aynı anda aynı zeminde birleştirilebilir. 
6. Post-modernizmin ilkesi ilkesizliktir. Çelişkili karşıt ögeler yan yana kullanılarak şaşırtıcılık elde edilir.

7. Sıradan olandan, karmaşadan, hatta kitsch'ten, gündelik hayatın görünümlerinden korku duymaz, benimser.

8. Sanatçı topluma biçim verme iddiasında değildir.

9. Modernizmin ya öyle, ya böyle katılı̆̆ına karşı post-modernizmin hem öyle, hem böyle mantığ1, çoğulcu bir anlayışı savunur.

10. Post-modernizm geç dönem kapitalizmi ile yakın ilişki içindedir. Post-modernizm ABD’deki mali birikimin bir uzantısı olarak yorumlanabilir. Ayrıca eklektik bir yapıya sahip olduğu için piyasa ruhunu da yansitmaktadir.

11. Post-modernizm bir kolajdır. Geçmiş ile geleceği birleştirmeyi öngörür.

Post-modern sanat anlayışı ile yaratıcı drama arasındaki en önemli benzerlik tüm kavramların yeniden sorgulanması, yeniden değerlendirilmesi sürecidir. Post-modernizmde olduğu gibi yaratıcı dramada da çok seslilik hakimdir, bütün mevcut seçenekler aynı anda aynı zeminde birleştirilebilir. Nasıl postmodernizm geçmiş ile geleceği birleştirmeyi öngören bir kolajsa, yaratıcı dramada insanın yaratıcı düşüncesini geliştirebilecek bütün disiplinleri, yöntem ve teknikleri içinde barındırmaya çalışan bir kolajdir.

Avant- garde sanat ve Post-Modernizmin anlayışı ile büyük benzerlik gösteren bir başka çağdaş sanat akımı kavramsal sanat akımıdır.

Kavramsal Sanat: Sanatı bir bütün olarak ele alır. Daha önce sanat denildiğinde bir ürünle sonuçlanması beklenirken (resim, heykel, roman vb.) kavramsal sanatta sanatçının iletmek istediği düşünce ve kavram öne çıkmıştır. Kavramsal sanatın en önemli özelliği düşünceyi/kavramı iletmede araç olarak dili, çeşitli nesneleri, insanın kendisini ya da doğayı kullanmasıdır.Kavramsal sanat için önemli olan düşüncenin üretim ve sunum sürecidir. Sonuç yani sanatsal yapıt ikinci plandadır. Hatta bir sanat yapıtı olmayabilir.

$\mathrm{Bu}$ yaklaşım yaratıcı drama yöntemi için de söz konusudur. Yani yaratıcı drama çalışmalarında da sonuç değil süreç önemlidir. Kavramsal sanat, sanatı seyredilmekten kurtarmış, izleyicinin katılımını öngörmüştür. Kavramsal sanata göre sanat yapıtı insanın zihninde oluşmaktadır. Amaç bir sanat nesnesi yaratmaktan çok, belli bir konuda düşünmek, o konuyu algılamak, yorumlamak ve eleştirmektir. Böylece sanat yalnız sanatçıların ürettiği sanat yapıtları ile sınırlı kalmaz. İzleyicilerin katılımı ile sanatçının yaratıcılığı bulunmuş olur. Kavramsal sanat sanatlar arasındaki sınırları kaldırıldığı gibi, 
sanat, belli bir kesimin tekelinden kurtarılmıştır. Hemen hemen aynı dönemin bir başka sanat akımı da Fluxus'tur.

Fluxus (Çokluk): Bu sözcüğü 1961 y1lında Fluxus'un öncülerinden George Mociunas, New York'ta A/G adlı galeride verdiği bir dizi konferans için kullanmıştır. Maciunas bu sözcüğü Fluxus tanımlarının çokluğundan dolayı kullanmıştır.

Aşağıda sıralanan Fluxus ölçütlerine dikkat edilirse yaratıcı drama ile bağlantısı kendiliğinden ortaya çıkar.

1. Küresellik Fluxus'un merkezidir. Bu aynı dünyada yaşadığımızı, siyasi sınırların doğal ve kültürel olmadığı gerçeğini belirler.

2. Fluxus'ta en bilinçli amaç, sanatla yaşam arasındaki sınırları yok etmektir. Yani sanat resim, tiyatro, müzik v.b. sanat dalları ile sınırlı olmadığı gibi, sanatın her yerde sokakta, markette yapılabileceğini savunur.

3. İntermedia, Fluxus için uygun bir araçlar sistemidir. Eğer sanatla yaşam arasında bir sınır yoksa sanat formları arasında da ayrım yoktur.

4. Fluxus sanata bilimsel yöntemi uygulamıştır. Deneysellik, araştırmacılık ve tabu kırııılık onun ilkeleridir. Deneysellik yeni şeyler denemek ve sonuçları derlemek demektir. İyi sonuç veren deneyler, deney olmaktan çıkar, kullanışlı birer araç olur.

5. Fluxus'un bir özelliği de şansı önemsemesidir. Şans yöntemi ve sonuçları Fluxus sanatçılarının işlerinde oldukça sık görülür. Şansın özellikle rastlantı anlamında Dada’ya, Cagé’e ve Duchamp’a kadar uzanan bir geleneği vardır.

6. Oyunsallık, Fluxus'ta başından beri vardır. “Şakalar, bilmeceler, eğlenceler, olaylar, v.b.” Fluxus sanatçılarının hemen hepsi mizahı kullanır ama oyun mizahtan daha geniş anlam içerir. Buradaki oyunsallık; düşüncelerin oyunu, serbest deneyim oyunsallığı, bilimsel deneye olduğu kadar, yaramazlığa da yakın olan kavramlardır.

7. Fluxus çalışmalarında sadelik ve tutumluluk, gerçek ve güzellik arasındaki ilişkilere gönderme yapılır. Burada söz edilmesi gereken diğer bir kavram da zerafettir.

8. Kapsayıcılık: İdeal bir fluxus işi birçok başka işi de kapsamalıdır. Bu ilke zerafet ve tutumluluk fikirlerinin sonucudur. Fluxus'un deneyselciliğe ve bilimsel yönteme olan yakınlığı burada görülebilir. 
9. Temsiliyet ilkesi: Bu ilkeye göre bir teoriyi örnekleyen işin niteliği ve onun çatkısının anlamıdır. Tüm fluxus işleri kuşkusuz bir şeyi temsil edici değildir, ancak öyle bir ortak duygu vardır ki, öyle olanlar ideale daha yakındır.

10. Özgürlük kavramı: İşin özgür, kendine yeterli ve tüm parçaları içeren bir durumda olmasıyla ilintilidir. Fluxus'ta birçok sanat yapıtı, birden fazla anlama gelme ve yeni anlamlar oluşturabilmek için anlam kaydırma üzerinde kuruludur. Eğer bir işte özgürlük varsa, ona anlam oldukça bilinçli bir şekilde yüklenmiştir. Bir bakıma, felsefi çok anlamlılığı ve köktenci dönüşümü sembolize eden bir sanat hareketiyle çelişkili görünse de, bu kavram Fluxus'un temel fikirlerindendir.

11. Birçok Fluxus işi zamanın içinde yer alır. Bazen bu durum "geçici" sözcüğüyle ifadelenmiştir. Fluxus'un performanslarında ve yayın üretiminde geçicilik niteliği açıkça ortadadır. Ancak Fluxus işlerinde değişik bir süre duygusu vardır. Günler, ya da haftalar süren müzikal parçalar, on yıllar boyunca süren performanslar, hatta oldukça uzun sürelerde gelişen ve evrimleşen sanat yapıtları gibi. Zaman, insan varlığının yüce durumu, Fluxus’ta merkezi bir yere sahiptir.

Fluxus'un en önemli özelliklerinden biri disiplinlerarası olması ve izleyicilerin dikkatini basit, iyi tanımlanmış eylemler ya da eylemler dizisine yöneltmesidir. Fluxus sanatçılarında toplumsal kaygılar, estetik düşünceden önde gelir. Geleneksel tavır ve tutumları yıkmak isterler. Ancak amaçları popüler kültürü canlandırmak değil, yepyeni bir bakış açısı yaratmaktır. Çağdaş sanatın öncülerinden sayılan Joseph Beuys akımın en önemli temsilcilerindendir. Yaşamı boyunca sanat, sanatçı, sanatın yeri ve işlevi konularında birçok soruyu gündeme getirip tartışan Beuys yaptı̆̆ 1 eylemlerle de izleyicinin kafasında sorular uyandırmayı amaçlamıştır.

Beuys'un sanatın temeline koyduğu kavram 'Eylem'dir. Eylem, sanatçı-sanat edimi ve sanat yapıtı üçlüsünü tek bir çerçevede birleştirir. Yapıt, sanatçının yaptığı eylemin kendisidir; sanat galerisinde sergilenecek nesneler ise eylemin yapıldığg mekan ya da eylemden arta kalan tortudur. Beuys, savaş sonrası Almanya'sının uluslararası ün kazanan ilk sanatçılarındandır. Bu ün, onun fikirleri ve sanatsal stratejileri, farklı materyal ve teknikleri ustaca bir araya getirişi kadar; bu materyallere ilişkin çağrışımları duyarlı ve kusursuz bir şekilde yönetme, içlerinde saklı olan potansiyeli ortaya çıkarıp yeni kanallara yönlendirme yeteneği ile de kazanılmıştır. Yapıtlarında, giderek gerçeklikten kopan, birbiri ile uyumsuz yönetim sistemlerine bölünerek parçalanan bir dünyanın açık yaralarına parmak basar. Beuys, evrensel bir gerçeklik fikrine sahiptir. Bu gerçeklik, yarattığı tüm sanatsal çalışmaları da içine alır. Her bir yapıt, onun dünya görüşünün bir yansımasıdır. Aynı şekilde, somut gerçeğin normal imgesine, bir karşı imgeyi de içerir. Beuys'un sanatsal yaklaşımı yalnızca resim, heykel, baskı gibi geleneksel teknik ve disiplinleri değil, insan varlığının her alanındaki tüm yaratıcı etkinlikleri de içine alır. Sanatı, her 
şeyin bir akış (flux) halinde oluşu fikrine dayanır. Dolayısıyla bir sanat yapıtı, kesin ölçütlere, kategorilere ya da formlara zorunlu kılınamaz.

Beuys'a göre herkes bir yaratıcı gizil güce sahip olduğundan 'herkes sanatçıdır' ve sanatçı olarak herkesin işlevi, olagelen kültürün temel koşullarını sorgulamaktır. Beuys, insanın gizil gücünü geliştirmek yerine yalnızca kanalize eden kısıtlayıcı işlevleri uygulayan geleneksel okulları; bürokratikekonomik baskı ile bunun sonucu ortaya çıkan uluslararası kitle kültürünü eleştirir. Beuys'un sanatı izleyicinin aktif katılımını talep eder. Beuys, düşünmenin kendisinin sanatsal eylemin bir parçası olduğunu belirtir.

J.Beuys'un sanat adına yaptığı birkaç çalışmayı kısaca özetlersek:

Ölü bir tavşana tabloları nasıl açıklamalı, (1965): J.Beuys bir resim galerisinde kucağındaki ölü bir tavşanla, kafasına bal dökmüş ve tek bacağı keçeye sarılı olarak bir taburede oturur; kucağındaki tavşan ölüdür: Sağ ayağı demir pençeye bağlıdır, diğeri ise aynı büyüklükteki bir pençe üzerinde durmaktadır. Düşünce organı olan kafa ölü gibi donup kalmıştır, bal ise, canlı tözüyle düşüncenin de canlı olabileceğini seyirciye telkin eder. Seyirci burda ölü bir hayvanın bile birçok insandan daha fazla sanat anlayışına sahip olduğunu farkettirmeye çalışır (Resim 2).

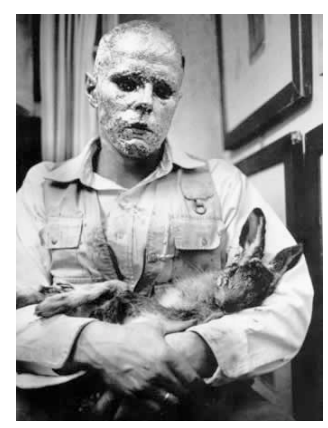

Resim 2: Joseph Beuys: Ölü bir tavşana tabloları nasıl açıklamalı?

İki Müzisyen için Kompozisyon (1963): Kurularak çalışan müzikli oyuncakların zembereklerini kurar ve her birinin farklı aralıklarla durmalarını bekler.

Sibirya Senfonisi, 1.Satz (1963): Kara tahta, ölü tavşan, piyano, elektrik telleri ve benzeri nesneleri kullanarak sahnede karmaşı bir eylem sergiler.

Yukarıdaki Beuys'a ait özel birkaç örnekten anlaşılacağı gibi Fluxus hareketi sanat yapıtından çok yaratıcı düşünceyi ön plana çıkarmıştır. Yaratıcı drama çalışmalarında da yaratıcı düşüncenin geliştirilmesi ve ortaya çıkarılması süreci önem taşır.

Fluxus'un ölçütlerinden büyük bir çoğunluğu sanat eğitimi çalışmalarında kullanılabilir. Yaratıcı dramada sanatsal çalışmalar programlanırken Fluxus sanatçılarının çalışmalarından büyük ölçüde 
yararlanılabilir. Özellikle doğaçlamalarda, zerafet, tutumluluk fikirlerinden; deneysellik, araştırmacılık, tabu kırıcılık ilkelerinden; şans yönteminden; oyunsallık yaklaşımımdan yararlanılabilinir.

Happening (Oluşumlar): Oluşumların ilk uygulamaları 1961 yılında New York'ta Amerikalı sanatçılar tarafından gerçekleştirilmiştir. Oluşumlar; görsel tiyatro özellikleri taşırlar. 1908 yılında kurulan Münih Sanatçıları tiyatrosundan, gerçeküstü/ dışavurumcu tiyatrodan, uyumsuz tiyatrodan ve Rus tiyatrosundan bazı özellikler taşımasına rağmen bu yaklaşımlardan farklıdır. Oluşumlardaki gösterimler ses, gürültü ve kimi kez koku kullanılarak sahne nitelikleri ortadan kaldırılmış üç boyutlu bir hareket mekanı içinde oyuncu etkinliklerini, diğer çevresel ve yapay malzemelerle birlikte nesnel ve rastlantısal görülen bir yaklaşımla bir araya getiren sunulardır. Oluşumlarda belli bir olay bütünlüğü, zaman, yer ve konu yoktur. Oluşumların kurguları düzenlenmiş olmaktan çok, farklı olguların birleştirilmiş olmasına bağlıdır. Genellikle olağan beden hareketleri, oyuncu/seyirci ayrımının ortadan kaldırılması gibi yaklaşımlarda edebiyat, sinema, tiyatro, müzik, dans ve daha birçok sanat dallarından etkilenir. Oluşum hareketi içerisinde yer alan sanatçıların çoğu disiplinlerarası bir tavır sergilemelerine karşın ressam ya da heykel kökenli sanatçılardır. Görünüşlerindeki rastlantısallığa karşın oluşumlar genelde önceden hazırlanmış bir senaryoya göre prova edilmiş olarak sunulurlar (Erzen, 1997).

Land Art (Çevresel Sanat): Endüstri sonrası Batı ülkelerinde ekolojik ilgilerin geliştiği 1960'lı yılların sonunda ortaya çıkan ve 1970'lerde tüm Batı ülkelerinde etkin olan bir sanat akımıdır. Çevreye ve özellikle doğaya yönelik olup toprak, taş ve benzeri doğal malzemeyle gerçekleştirilen sanatsal ürünleri içerir. Doğada hendekler açma, toprağa gömme, ıssız arazilerde yapılar gerçekleştirme, galeri mekanları içinde toprak, gübre, taş, moloz ya da insan ürünü çevresel gereç ve sergileri yerleştirme, mekanları 1şıklarla, eşya ile düzenleyerek çevresel boyutlarını ve niteliklerini vurgulama uygulamalarını içerir. Çekilen fotoğraflarla ya da video çekimiyle yapılanlar belgelenir. Yapılanlar geçicidir, yapıtın satın alınabilmesi mümkün değildir. Yapılan işin masrafı satışa çıkarılan fotoğraflardan karşılanır. Bazı bölgelerde planlarını gerçekleştirmek için sanatçıların işçi ve makine kullanması gerekir. $\mathrm{Bu}$ tür çalışmalarında sanatçılar yeryüzeyinin büyük parçalarını yeniden düzenlerler, ırmakların donmuş yüzeylerini çeşitli motifler uyarınca keserler ya da yeni sürülmüş bir tarlayı tırmıkla düzenleyerek yeni şekiller oluştururlar. Sanatı geleneksel değer yargılarından kurtarma çabası, sanatçıların sanat yapıtının metaya dönüşmesine, parayla satın alınabilmesine ve böylece belirli ekonomik kesimlerin beğenisine hizmet etmesine karşı önlemler alınmasına yol açmıştır.

Öte yandan, sanatçıların çevredeki gizil gücün farkına varmaları, gerçeklere daha yakından sahip çıkma arzuları ve sanatın sınırlarını yeni gereç ve uygulamalarla genişletme deneyimleri çevrenin de bir sanat olayı için kullanılmasında önemli bir rol oynamıştır. Çevre özellikle endüstrileşme ve makineleşmenin toplumsal yaşamı ve doğayı geniş ölçüde olumsuz etkilediği XX. yüzyılda gittikçe 
artan bir önem kazanmaktadır. İnsan için çevreyi ve yaşam ortamını en az sıkıntılı hale getirmek yüzyılın önemli toplumsal zorunluluğu olmuştur. Çevresel sanatlar, mimari yapıların estetik formları, kentsel peyzajlar, hatta inşaat şantiyelerinin geçici duvarları, fabrika bacaları, sanatsal müdahalelerle çevreye hoşa giden bir görünüş vermeyi amaçlamaktadırlar. Bazı hallerde, kent ölçüsünde parklarda, meydanlarda sanat yapıtları sergilenmekte ya da doğa ve yapılara sanatsal formlar verilebilmektedir. Çevreye yapılan yeni müdahaleler, yerleştirilen yeni öğeler, kişilerin doğayı ve çevreyi yepyeni bir biçimde algılamalarına, farkına varılmayan nitelikleriyle görmelerine, olağan bir yaşam akışı içinde dikkat edilmeyen özelliklerine dikkat etmelerine yardımcı olmaktadır. Giderek buldozerlerle, dinamitle tüneller ve hendekler açılmasına, ırmaklara, deniz kıyılarına yeni bir biçim verilmekte, hatta uygarlıktan çok uzak yerlerde yeni bir takım çevreler yaratarak bunların belgelenmesine dönüşmüş olan bu sanat, temelde doğa ve çevre ilgisine karşın bazı durumlarda doğayı tahrip etmiş, bu yüzden ağır eleştiriler de almıştır.

$\mathrm{Bu}$ tür sanatın karakteristik özelliği kullanışsızlık ve yararsızlıktan çok, olumlu yöndeki mantıksızlığıdır. Görünürde hiçbir anlamı olmayın, geçici bir iz bırakmak için düşünce, emek ve malzeme harcanmıştır. Peki, bu büsbütün amaçsız bir çaba mıdır? Eğer iyice düşünecek olursak bunların, insanların ve maddelerin sömürülmesine karş1; 20.yüzyıl kentinin hemen tanınan özelliği olan inşa etme ve yıkmaya karşı; doğa ve zaman önünde insanın küstahlığına karşı duyulan birer tepki olduğu anlaşı1ır.

Yaptığı uygulamaların büyük ölçeğinden ve göz alıcılığından ötürü adı en fazla yankı uyandırmış olan arazi sanatçısı CHRİSTO'dur. Christo çalışmalarında bir tiyatroyu, daha sonra da, birkaç tarihi yapıyı paketlemiş̧tir. Yöre halkı yakından tanıdığı bu yapıları, naylonların altında gizlenmiş görünce fazlasıyla etkilenmiştir. Christo'ya göre paketleme işi, anlık bir değişim olayıdır. Bu gizlenme, objenin gerçek kişiliğini bozmaz, tersine paketin altında yatan biçimlerin izleyici tarafından daha iyi gözlenmesini sağlar. Paketlediği nesneler arasında kaşık, şişe, iskemle, koltuk ve hatta kızlar da vardır. Sanatçı olağan koşullar altında ilgi çekmeyen nesnelerle yeni bir bakış açısı getirmek, insanların bu nesnelere yeniden bakmalarını sağlamak amacındadır (Resim 3).

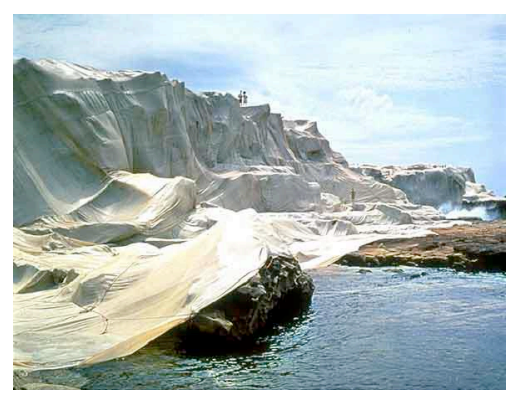

Resim 3: Christo 
Kısaca özetlenen sanattaki yeni yaklaşımların drama ve yaratıcılık alanında çalışanlar tarafından temel düzeyde de olsa bilinmesi, yeni düşünceler üretilmesinde önemli katkılar sağlayacaktır.

Bundan sonraki kısımda 2007 yılında gerçekleştirilen iki uluslararası sanat olayından bahsedilecektir.

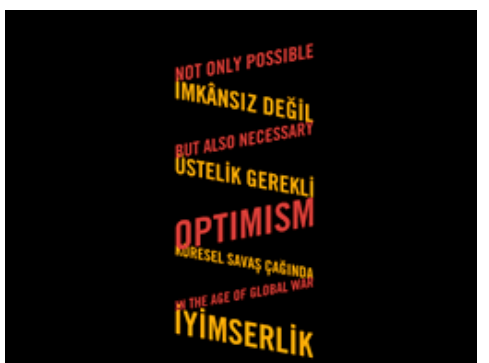

10. Uluslararası İstanbul Bienali

10. Uluslararası İstanbul Bienali kapsamında, 18 'i Türkiye'den olmak üzere dünya güncel sanat çevrelerinde tanınan ya da yeni keşfedilen 96 sanatçı ve sanatçı grubunun 150'yi aşkın projesi sergilenmiştir. İstanbul Kültür Sanat Vakfı tarafından düzenlenen 10. Uluslararası İstanbul Bienali 8 Eylül-4 Kasım 2007 tarihleri arasında San Francisco Sanat Enstitüsü’nün Sergi ve Halka Açık Programlar Yönetmenliğini yapan Hou Hanru'nun küratörlüğünde gerçekleşmiştir. 1987 y1lından bugüne, İstanbul Bienali uluslararası çağdaş sanatı Türkiye'ye sunma görevini üstlendi. Bu sergiyle hem sanat dünyasının son yirmi yıl içindeki hızlı gelişiminin İstanbul sanat çevresinin değişimine yansıması, hem de genç Türk sanatçı kuşağının uluslararası güncel sanat çevresine katılma süreci gözler önüne serilmektedir. Bienalin tarihçesini sunan ve yıllar boyunca bienal için çalışmış küratörlerin bakış açılarını izleyiciye göstermek amacıyla düzenlenen Şimdiki Zaman Geçmiş Zaman Sergisi için, İstanbul Modern Sanatlar Müzesi, Beral Madra, Vasıf Kortun, René Block, Rosa Martinez, Paolo Colombo, Yuko Hasegawa, Dan Cameron ve Charles Esche'den, düzenledikleri bienalde yer alan, ortaya koymak istedikleri yaklaşımı en açık şekilde ifade eden, en ilham verici ve simgesel yapıtlarını belirlemeleri istenmiştir. Her küratör kendi yönettiği bienali en iyi temsil eden üç sanatçı seçmiştir. Seçilen üç sanatçıdan birinin Türkiye'den olması da öngörülmüştür. ABD, Almanya, İskoçya, İspanya, İtalya, Japonya ve Türkiye kökenli olan küratörler, günümüz kültürüne damgasını vuran birçok kilit sanatçının yapıtlarını bir araya getirerek çok renkli bir görünüm oluşturmuşlardır. Sergideki yapıtlar, ilk bienalden sonuncusuna doğru ilerleyen zamandizinsel bir düzen içinde yerleştirilmiştir. Her bölümün başlangıcında yer alan ve söz konusu bienale ilişkin belgesel kayıtları bir araya getiren plazma ekranlar, özgün olarak sergilenmiş yapıtların oluşturduğu geniş yelpazeyi ve sergilendikleri özgün mekânları gözler önüne sermiştir. Uluslararası İstanbul Bienali’nin 20. yıldönümünü vurgulamak amacıyla düzenlenen Şimdiki Zaman, Geçmiş Zaman sergisinin, çağdaş sanat ve çağdaş sanatın olanakları hakkında birçok farklı düşünceyi aynı anda dile getirdiğini belirten İstanbul Modern Sanatlar Müzesi Direktörü ve serginin eşküratörü David Elliott, "Bir açıdan, kentin gelişim sürecindeki tekil bir 
dönemin kaydı olan sergi, bir başka açıdan, geçtiğimiz yirmi yıl içinde sanatın ve estetik düşüncenin değişimini yansıtan tarihsel bir okuma, bir diğer açıdan da, küratörlerin ve bienallerin dünya çapındaki yükselişini inceleyen bir durum değerlendirmesi olarak görülebilir. Geçmişle gelecek arasında bıçak sırtı bir denge yaratan sergi, kahramanca ve belki de mağrur bir şekilde, bugünü yakalamayı ya da en azından anımsamayı hedefliyor. Sergide görecekleriniz bu muammayı ve çok daha fazlasını gözler önüne seriyor." diyor.

\section{İmkansız Değil Üstelik Gerekli!}

10. Uluslararası İstanbul Bienali’nin kavramsal çerçevesi “İmkânsız Değil, Üstelik Gerekli: Küresel Savaş Çağında İyimserlik” olarak belirlenmiştir.

\section{Bienal Mekânları}

Atatürk Kültür Merkezi’nde kentsel yaşama dair, ütopya kavramına odaklanan 13 proje yer almaktadır. Bazı projeler sanatçıların AKM binasının tarihi ve gerçekliği üzerine yaptıkları derinlemesine araştırmaya dayalı olarak ve özellikle bu mekân için yaratılmıştır. AKM'deki projelerin teması ise "Yakmalı mı Yakmamalı mı?" olarak belirlenmiştir. İstanbul Manifaturacılar Çarşısı blokları güncel sanat için sergi mekânı olarak ilk defa kullanılmaktadır. Hou Hanru, İMÇ bloklarının tarihini, mimarisini ve işlevini göz önünde bulundurarak bu mekânın, "Dünya Fabrikası" teması çerçevesindeki projelere ev sahipliği yapmasına karar vermiştir. İMÇ'deki sergi, küreselleşme çağında dönüşen üretim biçimleri ve çalışma hayatına dair projeler içeriyor. Antrepo No.3'te uluslararası göç, iletişim ve kentlerdeki sınır alanlarına ilişkin çalışmalar gerçekleştiren 43 sanatçı ve sanatçı grubunun 'SINIRLAR' başlıklı yapıtları yer almaktadır.

\section{Uluslararası İstanbul Bienali'nden örnek çalışmalar:}

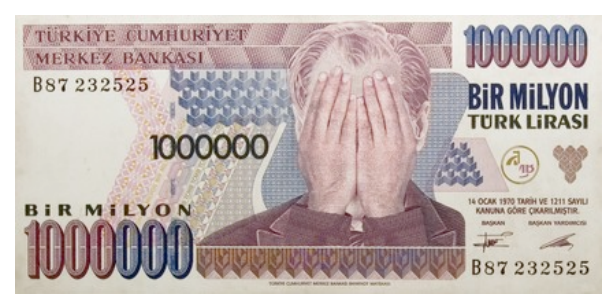

Resim 4: Halil Altındere

Halil Altındere'nin “Tabularla Dans” adlı yapıtında, ellerin, para ve kimlik üzerinde dramatik bir şekilde kullanılarak yüzün kapanmasına eşlik etmesi, izleyicinin bu örtünme/saklanma/başka mekâna kayma duygusunu ciddiyetle kurcalaması için yeterli bir nedendir. Fotoğrafıyla paranın varlığına anlam 
yükleyen Atatürk, örtünme eylemiyle aslında kendisine ait olmayan bir durumdan saklanarak, bizi saklanılan şey üzerine düşünmeye çağırır. Çöken bir ekonomik yapının en yalın işareti olan bol sıfırlı para, hemen bu yapının yanı başında gözlenen çürüme halinin de eğretilemesidir. 1995 yılında, Türkiye, dünya üzerindeki en yüksek rakamlı banknotları dağıtıma soktu: 1 milyon liralık banknotlar, o dönemde aşağı yukarı 2 Amerikan dolarına karşılık gelmekteydi. Ekonominin, 1980’lerdeki hızlı liberalleşmesi refah seviyesinin de yükselmesini sağladı ama enflasyonun da hızla yükselmesine ve Türk lirasının dünyanın en değersiz para birimi olmasına neden oldu. Halil Altındere, mizah aracılığıyla, izleyiciyi, paranın gerçek değerini değerlendirmeye ve ulusların ve ekonomilerinin kullanabilecekleri gurur ya da utanç vesileleri üzerine düşünmeye davet ediyordu.

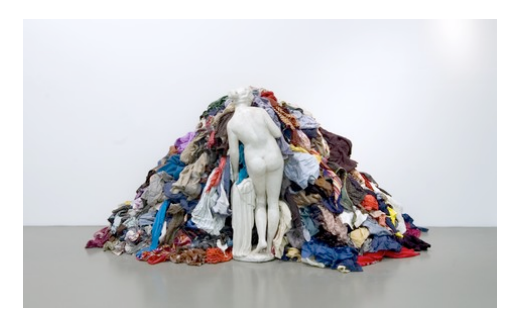

Resim 5: Michelangelo Pistoletto

Arte povera (yoksul sanat) akımının öncülerinden ve çağdaş sanatın en önemli isimlerinden biri olan Michelangelo Pistoletto'nun 1987 tarihli Paçavraların Venüs'ü adlı yapıtı, serginin en önemli ve heyecan uyandırıcı yapıtlarından biriydi. Eski kıyafetlerden ve paçavralardan oluşmuş bir yığının önüne yerleştirilmiş bir "Venüs" heykelinden oluşan yapıt, dünya hâkimiyetinin batılı perspektiflerini ve merkez/çevre basmakalıplarını tüm dünyada konuşulmadan önce sorgulayan öncü bir yapıt olma özelliğini taşıyor. Bu yapıtında, Michelangelo Pistoletto, aşk tanrıçası Venüs'ü betimleyen klasik bir heykelin röprodüksiyonunu kullanıyor. Heykelin duruşu, meşhur efsanedeki, yıkanmak için suya giren Venüs'ün bir şeye şaşırdığı ve elleriyle bedenini örtmeye çalıştığı anı temsil eder. Genellikle böyle bir yapıt, izleyicinin, duruşun erotik biçimin görebilmesine izin verecek şekilde, ön taraftan izlenir. Oysa Pistoletto, heykeli, yüzü bir paçavra yığınına doğru dönmüş şekilde yerleştirerek, yapıtın geleneksel anlamını değiştirir ve esprili bir alternatif öykü önerir: Venüs çıplak bedenini artık bu paçavralarla örtebilecektir. Sanatçı bu yolla, gündelik malzemeler lehine geleneksel değerlere ve estetik yaklaşımlara sırtını dönen, sanat konusunda yeni bir demokratik anlayış önerir. Pistoletto paçavraları kullanmaya 1967'de başlamıştı. O dönemde sanatsal imgeleri dikte ettirir görünen baskıcı toplumsal yapıların iptal edilmeye başladığı ve yalnızca görünümler aracılığıyla, altta yatan gerçeklikleri görebilmenin mümkün olmaya başladığı bir dönemdi. Hem Doğu'da hem de Batı'da var olan güçlü öğretinin hayaletleri, dışlanmışların- dünyanın hemen yer yerinde var olan ve genellikle toplumun ayaktakımı olarak görülen sıradan ve umutsuz cemaatlerin; Üçüncü Dünya'nın yoldan çıkmış, yozlaşmış kitlelerinin, kadınların, 
mahkumların kargaşası ve çok değerliliğiyle doğrudan bir karşıtlık oluşturuyordu. Onlar toplumun paçavralarıydılar. Bu yapıtının akışkan karakteri, sonsuz yorumlama olasılıklarına izin veriyor: her bir okuma, yığının içinden seçilen bir paçavraya eş değer. Yapıt, herhangi bir bağlama yerleştirilebilir, içine yerleştiği bağlama göre anlam değiştirebilir, hatta mizahi öğeleri bile barındırabilir.

2007 yılında 10 Haziran-21 Kasım tarihleri arasında düzenlenen Venedik Bienali 52. Uluslararası Sanat Sergisi'nde Türkiye'yi “Don't Complain” başlılı enstelasyonuyla Hüseyin Alptekin temsil etmiştir.

\section{Hüseyin Bahri Alptekin}

Hüseyin Alptekin'in "Don't Complain" adlı eseri bir dizi tek hücreli odanın birbirine yarım ay biçiminde kenetlendiği bir enstalasyondan (yerleştirme) oluşuyor. Her odada ayrı bir zihinsel alan kurgulanıyor. Sergideki her odacığın içinde, LCD ekranlarda, art arda gelen imgeler yer alıyor. Hüseyin Alptekin'in "incidents" (küçük vakalar) diye adlandırdığı bu imgeler uzun süreler boyunca benzer yerlerden çekilen anlık fotoğrafların art arda gelerek birleştirildiği anlatısal videolardan oluşuyor. Sanatseverler, gerçek bir ev gibi düzenlenen mekânları gezerken, odalarda yer alan iskemle ve koltuklara oturabilecek ve videoları izleyebilecekler. Hüseyin Alptekin aralarında 1995 yılında 4. ve 2005'te 9. Uluslararası İstanbul Bienalleri, 24. Sao Paulo Bienali (1998), 4. Cetinje Bienali (Surbistan Karadağ, 2004), Manifesta V, 47. "Ekim Salonu: Sanat, Yaşam ve Kargaşa" sergisi (47th October Salon: Art, Life and Confusion, Belgrad 2006) ve 2003 yılında Walker Art Center'da gerçekleştirilen “Coğrafyalar Nasıl Biçim Alır” (How Latitudes Become Forms) sergisinin de bulunduğu birçok sergi ve sempozyuma katıldı. Türkiye Pavyonu'nun açılış etkinleri çerçevesinde 8 Haziran Cuma günü San Servolo Adası'nda bir de parti düzenleniyor. Türk Pavyonu Açılış Partisi’nde kökleri halk müziğine dayanan, konserlerinde gerek canlı çizim tekniği gerekse dans performansları ile dünyanın her yerinde ilgi gören Baba Zula sahne alır.
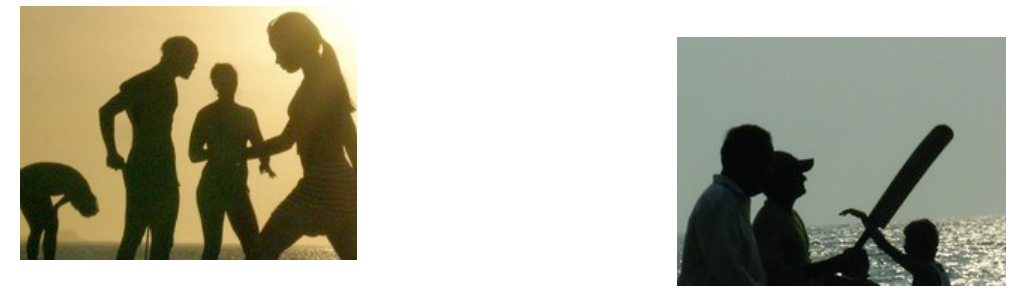

Resim 6: . "Don't Complain” (Şikayet Etme)

Hüseyin Alptekin'in Venedik Bienali'ndeki sergisinin başlığı "Don't Complain" (Şikayet Etme) aynı zamanda sergi için hazırladığ 1 1şıklı tabelada da yazan cümle. Bu çelişkili başlık bir hoşnutsuzluk 
içeriyor. "Şikayet etme" diyen kişi de şikayet etmektedir. Bu hoşnutsuzluğun nedenleri hakkında olduğu kadar, kimi kime şikayet edildiğine dair bir kuşku da uyandırmakta.
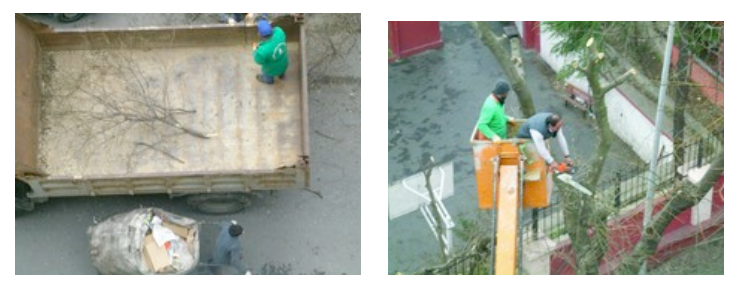

Bir başka "incident"ta ise, Alptekin sokakta yaşayan dilsiz bir siyah çöp toplayıcısının hayatını dört mevsim boyunca izliyor. Kaydedilen, bu kişinin sokak köşesinde, terkedilmiş bir arabanın çevresinde, bir çöp bidonun yanında dönen hayatıdır. Belediye çöpçüleri ve mahallenin müdavimleri ile gayriresmi bir ekonomi ve mahzur görülen bir illegalite, bir otoekoloji içinde, ta ki terkedilen araba çekilip götürülene kadar hayat sürüyor. Alptekin'in yerinden edilmişlerle, küreselleşmenin görünmez kıldıklarıyla, tasarlanmamış bu müellifsiz kozmosla benzer bir yörüngede süren empatik ilişkisi uzun yıllara dayanmaktadır. Sürekli yolcu oluşu, evinden ve yerel konumundan "kaçışı" başka mental mekânların görünmeyen ama tam da göz ucunda olan yönlerini kazıyan karıştırması belli bir bilgi nesnesi ve çalışma biçimi oluşturmakta.

Sonuç olarak bienallare bakıldığında yaşamı sorgulaması, var olan kavramlara farklı bir bakış açısı ile yaklaşması ve amaca ulaşmada tüm sanatlardan yararlanması, aynı zamanda sonuca ulaşmada sürecin gerekliliğini savunması açılarından yaratıcı drama alanında çalışanların yeni, özgün düşünceler üretmelerinde yol gösterici olacağı umulmaktadır.

\section{Kaynaklar}

Erzen, J. (1997). Eczacıbaşı Sanat Ansiklopedisi. İstanbul: Yem Yayınları. 


\title{
Summary
}

\section{Modern Trends of Art Overlapping Creative Drama Ayşe ÇAKIR ÍLHAN.}

\author{
Ankara University
}

If creativity is defined as creating a brand new object from existing ones, it becomes clear that creativity education should not be limited to school activities. Creativity may exist in any situation where people interpret the environment. Its development relies largely on art education. In other words, creative drama education is art education.

Throughout the history of humanity, art has centred on the environment at certain times, and on the inner world of the artist, or the artwork or the audience at other times. These are the indispensable parts of art. Whenever one of them was particularly emphasized, a different artistic theory or trend was born.

World War I (1914) coincided with the birth of the Industrial Revolution in England, Germany and France. As Switzerland remained neutral in the war, many artists from England, Germany and France fled to this country. Theatre actors, painters, ballerinas and artists from other branches of art who gathered there started the trend of Dadaism. This anti-war movement became a pioneer for other modern trends of art. Breaking the borders between different branches of art, the Dadaists engaged in interdisciplinary work and shows. Even though they had different aims, they made use of improvisations and happenings which are common in drama.

Below is a brief list of artistic approaches which may constitute examples for modern artistic trends and be used in creative drama studies:

The following assumptions may be made for Avant-Garde/Pioneering artistic implementations:

1. Avant-Garde art requires participation from the audience rather than passive viewing.

2. The real thing is not the object created but its construction and the way it is perceived. The real aim is to influence thought, perception and reaction. That is, the product becomes the mind.

3. Values are generally political as they are questioned.

4. Questioning methods do not yield definite judgments and values.

5. The priority is not on the object of art but on its creation.

6. It is against rational and fixed thinking. 
7. It concerns itself with originality and issues of copying.

8. It has a comprehensive approach towards art.

9. It brings down the borders of art with brave content, tools and definition.

10. It is against formalism and aesthetic orientation.

11. It is against using art as a commodity.

12. In societies with Avant-Garde art, artists are in the minority.

13. It emphasizes the originality of what is virtual and ordinary (Erzen, 1997).

Other concepts which are very similar to Avant-garde art are Post-Modernism and conceptual art. The qualities of Post-Modernism are as follows:

1. Modernism refers to the process of re-questioning and re-evaluating existing concepts.

2. Post-modernism does not call for the abolishment of modernism. It takes modernist trends, analyses them by using a modern perspective, tries to synthesize them and includes, as in all other concepts that start with the prefix "post", the meaning of deviating from principles and degeneration.

3. In post-modernism the past is used and consumed freely.

4. Post-modernism is open to research and experimentation.

5. Post-modernism contains multiple voices; all existing options may be combined in the same place at the same time.

6. The principle of post-modernism is being without principles. Conflicting opposites are used together to have a surprising effect.

7. It does not fear the ordinary, chaos, visions of daily life and even kitsch; it embraces them.

8. The artist does not attempt to shape the society.

9. In response to the rigid "either-or" approach of modernism, post-modernism defends a pluralist "both-and" approach.

10. Post-modernism is closely related to late capitalism. Post-modernism may be interpreted as an extension of the financial accumulation in the USA. As it has an electric substance, it reflects a market spirit too.

11. Post-modernism is a collage. It combines the past and the present. 
Just like the artistic understanding of avant-garde art and Post-modernism, the qualities of conceptual art are similar to the educational approach of creative drama.

Conceptual Art: Treats art as a whole. While in earlier times art was expected to result in a product such as a painting, sculpture or novel, the emphasis in conceptual art is on the thought or concept that the artist wants to convey. Another artistic approach that resembles creative art is a Happening. Happenings used sound, noise and sometimes smells in a three dimensional space unlike a stage to bring together artistic activities with other environmental and artificial materials in an objective and incidental approach. Happenings do not have a specific entirety of events, time, places or subjects. Far from being specially arranged, their story is based on the combination of different events.

In approaches such as the use of ordinary body movements and the elimination of actor/audience distinction, it has generally been affected by literature, cinema, theatre, music, dance and other branches of art. Although most Happenings artists display an interdisciplinary attitude, they are mostly painters or sculptors. Despite the incidentalism on the surface, happenings have generally been improvised according to a pre-designed scenario (Erzen, 1997).

Land Art: This trend originated in the 1960s when the post-industrial Western countries witnessed an increased interest in environmental matters. It became effective in all Western countries in the 1970s.

It is directed mainly towards the environment and the nature, and includes artwork made with soil, stones and other natural materials. Its efforts to free art from traditional value judgments have led to measures against turning artwork into a commodity and thus serving the taste of certain economic classes alone.

In brief, even a basic knowledge of such new artistic approaches will benefit those working in the fields of drama and creativity and help them generate new ideas. The following section mentions two international art events which took place in 2007. 10th International Istanbul Biennial hosted more than 150 projects by a total of $\mathbf{9 6}$ established and novice artists and art groups, $\mathbf{1 8}$ of whom were from Turkey. Organized by Istanbul Culture and Art Foundation, the 10th International Istanbul Biennial took place between 8 September - 4 November 2007 and boasted the curatorship of Hou Hanru who is the Director of Exhibitions and Public Programs of San Francisco Art Institute. The conceptual frame of the 10th International Istanbul Biennial was "Not Impossible, But Necessary: Optimism in an Age of Global War". This year, Hüseyin Alptekin represented Turkey in the Venice Biennale 52nd International Art Exhibition running between 10 June-21 November 2007, with an installation named "Don't Complain". 
